City University of New York (CUNY) CUNY Academic Works

2014

\title{
A Simple Treatment of the Liquidity Trap for Intermediate Macroeconomics Courses
}

Sebastien Buttet

CUNY Guttman Community College

Udayan Roy

Long Island University - C W Post Campus

\section{How does access to this work benefit you? Let us know!}

More information about this work at: https://academicworks.cuny.edu/nc_pubs/2

Discover additional works at: https://academicworks.cuny.edu

This work is made publicly available by the City University of New York (CUNY).

Contact: AcademicWorks@cuny.edu 


\title{
A Simple Treatment of the Liquidity Trap for Intermediate Macroeconomics Courses
}

\author{
Sebastien Buttet and Udayan Roy*
}

November 9, 2013

\begin{abstract}
Leading undergraduate textbooks of intermediate macroeconomics now include a simple reduced-form New Keynesian model of short-run dynamics (alongside the IS-LM model). Unfortunately, there is no accompanying description of how the zero lower bound on nominal interest rates affects the model. This paper shows how the aforementioned model can be modified simply to teach undergraduate students about the significance of the liquidity trap for economic performance and policy. This acquires additional significance because economies such as the United States and Japan have been close to the zero lower bound since 2008 and 1995, respectively. We show that, when the zero lower bound is introduced, an additional long-run equilibrium exists. This equilibrium is unstable and can lead to a deflationary spiral. We find that both fiscal and monetary policy can keep an economy out of a deflationary spiral whereas only fiscal policy can end a deflationary spiral that has already begun.
\end{abstract}

JEL Classification: E12, E52, E62

Key Words: Intermediate Macroeconomics, Zero Lower Bound, Monetary Policy, Fiscal Policy

*Economics Department, Long Island University, Brookville, NY 11548. Email: sebastien.buttet@liu.edu. Phone: (516)299-4089. Thanks to Veronika Dolar for helpful comments. All errors are ours. 


\section{Introduction}

The Great Recession of 2008-9 has changed the practice and teaching of macroeconomics. New editions of prominent textbooks have added entire chapters on the crisis and its aftermath. The economy-wide ripples of developments in the financial sector have received considerable coverage. The zero lower bound on nominal interest rates is no longer ignored or treated as a curiosity. In this paper, we demonstrate a simple way to improve the integration of the zero lower bound into the discussion of short-run macroeconomic theory and policy in undergraduate macroeconomics textbooks.

Even a cursory look at recent editions of prominent undergraduate macroeconomics textbooks such as Mankiw (2013) or Jones (2011) shows that the IS-LM model is being supplemented by a reduced-form New Keynesian model consisting of the IS curve, the expectations-augmented Phillips curve, and a monetary policy rule for the central bank. Unfortunately, in these textbook discussions, the central bank's monetary policy rule simply ignores the zero lower bound (ZLB); the zero lower bound is often mentioned, but it is not built into the theory. This will not do in a world in which the central banks of the United States and Japan have kept their policy rates near zero since 2008 and 1995, respectively. Bright and curious students will inevitably ask their instructors how the graphs of the New Keynesian model that they have been taught would look when the central bank is at the zero lower bound. In this paper, we show that the integration of the zero lower bound into the New Keynesian model is remarkably straightforward and can yield interesting insights into, for instance, the dreaded phenomenon of the deflationary spiral.

In several of today's undergraduate macroeconomic textbooks, the dynamic properties of New Keynesian models are analyzed with two curves - a negatively-sloped aggregate demand curve and a positively-sloped aggregate supply curve - that link inflation and output. The intersection of these two curves determines equilibrium output and inflation. In this paper, we add the explicit requirement that the nominal interest rate set by the central bank must be non-negative. We show that the familiar negatively-sloped aggregate demand curve we see in textbooks becomes a kinked curve with a negativelysloped segment (when the ZLB is non-binding) and a positively-sloped segment (when the 
ZLB is binding). The positively-sloped segment captures the idea that falling inflation is a special nightmare at the zero lower bound. As nominal interest rates cannot be reduced any further, any decline in current inflation means an increase in the current real interest rate which in turn reduces aggregate demand and output.

The kinked demand curve generates two (rather than one) long-run equilibria: (i) a stable equilibrium where nominal interest rates are positive and inflation is equal to the central bank's target rate of inflation and (ii) an unstable equilibrium at which the nominal interest rate is zero and even the slightest shock can set off a deflationary spiral.

We show that the convergence properties of the economy depend on whether or not inflation is less than a tipping point level. As long as the inflation rate exceeds the negative of the natural (or, long-run) real interest rate the economy converges to the stable longrun equilibrium - even if the zero lower bound is initially binding. On the other hand, if inflation falls below the negative of the natural real interest rate, the economy enters a deflationary spiral with continuously falling inflation and output.

With regard to the effectiveness of monetary and fiscal policy in dealing with the deflationary spiral, we ask two questions: (i) What can be done to keep an economy away from the deflationary spiral? (ii) Can policy get an economy out of a deflationary spiral, if it is already in one? We show that expansionary fiscal policy is an adequate answer to both questions, while expansionary monetary policy - specifically, an increase in the target inflation rate - is a partial answer to (i) only.

The main ideas of our paper-(1) that the ZLB introduces a new long-run equilibrium, (2) that that equilibrium is unstable, (3) that the ZLB introduces a deflationary spiral, and (4) that there is a tipping point beyond which deflation leads to the deflationary spiral - have been explained here in the graphical form of Mankiw (2013, Ch. 15). All that an instructor who teaches that chapter would have to do is show (a) that the central bank's monetary policy rule does not always yield a positive nominal interest rate, and (b) that when the monetary policy rule yields a negative nominal interest rate the ZLB kicks in and the aggregate demand curve becomes positively sloped. Our four main results then follow immediately.

It is clear to us that unless the investment required - from both teacher and student- 
for a discussion of the ZLB is kept low, our treatment of the ZLB would be unlikely to be useful in the classroom. This is why we have expressed our analysis in the graphical style of Mankiw's Chapter 15 . We have shown that the main results that follow from the introduction of the ZLB can be taught to undergraduates with a simple change to Mankiw's (dynamic) aggregate demand curve. We believe that our paper sharply reduces the marginal cost of teaching the ZLB. And given that the ZLB introduces a whole bunch of interesting results, the marginal benefit of teaching Mankiw's Chapter 15 (or its counterpart in other textbooks) may now be higher for those instructors who currently skip the chapter.

Although our analysis builds on Mankiw (2013), to make our analysis relevant and useful for instructors who do not use that textbook, our penultimate section reviews the treatment of the zero lower bound in four other prominent intermediate macroeconomics textbooks: Blanchard and Johnson (2013), Carlin and Soskice (2006), Jones (2011), and Mishkin (2011). Several of these textbooks present algebraic-cum-graphical models in which the intersection of (aggregate) demand and supply curves determine output and inflation. However, none of them show how the ZLB affects their graphs. We explain how instructors who teach the New Keynesian model can modify their graphs and teach the ZLB with minimal hassle.

The remainder of the paper is organized as follows. In Sections 2 and 3, we introduce our model and characterize its long-run equilibria. We discuss the stability of these equilibria in section 4 . We study the policy responses to a deflationary environment in section 5 . We discuss the treatment of the zero lower bound in several notable intermediate macroeconomics textbooks in section 6 . We offer brief concluding remarks in section 7 .

\section{A Model of Short-Run Macroeconomic Dynamics}

Our goal here is to take a typical model of short-run macroeconomic dynamics from a standard undergraduate intermediate macroeconomics textbook and demonstrate how the analysis can be enriched if a non-negativity constraint on the nominal interest rate is added. The model that we have chosen to use is variously referred to as the dynamic AD-AS (or DAD-DAS) model in Mankiw (2013, Ch. 15), the AS/AD model in Jones 
(2011), and the 3-equation (IS-PC-MR) model in Carlin and Soskice (2006), where PC refers to the Phillips curve and MR refers to the central bank's monetary policy rule. This dynamic model has begun to supplement the static IS-LM model as the mainstay of short-run analysis in undergraduate macroeconomics textbooks. It is our belief that adding the zero lower bound to the teaching of short-run macroeconomic dynamics in undergraduate courses will increase the realism and relevance of the analysis because the interest rates used by central banks as their instruments of monetary policy have been close to zero for a long time in several countries. For example, the Bank Rate of the Bank of England has been at 0.5 percent since 2009. The Federal Funds Rate, which is the policy rate for the Federal Reserve in the United States, has been near zero since October 2008. The official discount rate in Japan has been close to zero since 1995.

For specificity, our paper looks at how the zero lower bound affects the DAD-DAS model in Mankiw (2013, Ch. 15). We begin by examinimg the five equations that drive Mankiw's DAD-DAS model. Equilibrium in the market for goods and services is given by

$$
Y_{t}=\bar{Y}_{t}-\alpha \cdot\left(r_{t}-\rho\right)+\epsilon_{t}
$$

where $\bar{Y}_{t}$ denotes the natural or long-run level of output, $r_{t}$ is the real interest rate, $\rho$ is the natural or long-run real interest rate, $\alpha$ is a positive parameter representing the responsiveness of aggregate expenditure to the real interest rate, and $\epsilon_{t}$ represents demand shocks. ${ }^{1}$ This equation is essentially the well-known IS curve of the IS-LM model, and it has no intertemporal dynamics. The shock $\epsilon_{t}$ represents exogenous shifts in demand that arise from changes in consumer and/or business sentiment - the so-called "animal spirits" - as well as changes in fiscal policy. When the government implements a fiscal stimulus (an increase in government expenditure or a decrease in taxes), $\epsilon_{t}$ is positive, whereas fiscal austerity makes $\epsilon_{t}$ negative.

The ex-ante real interest rate in period $t$ is determined by the Fisher equation and is equal to the nominal interest rate $i_{t}$ minus the inflation expected for the next period:

$$
r_{t}=i_{t}-E_{t} \pi_{t+1}
$$

Inflation in the current period, $\pi_{t}$, is determined by a conventional Phillips curve augmented to include the role of expected inflation, $E_{t-1} \pi_{t}$, and exogenous supply shocks, 
$\nu_{t}$ :

$$
\pi_{t}=E_{t-1} \pi_{t}+\phi \cdot\left(Y_{t}-\bar{Y}_{t}\right)+\nu_{t}
$$

where $\phi$ is a positive parameter.

Inflation expectations play a key role in both the Fisher equation (2) and the Phillips curve (3). As in Mankiw (2013), we assume that inflation in the current period is the best forecast for inflation in the next period. That is, agents have adaptive expectations:

$$
E_{t} \pi_{t+1}=\pi_{t}
$$

We complete the description of the DAD-DAS model with a monetary policy rule. Dynamic New Keynesian models assume that the central bank sets a target for the nominal interest rate, $i_{t}$, based on the inflation gap and the output gap, as in the Taylor rule (Taylor, 1993). Specifically, the DAD-DAS model in Mankiw (2013, Ch. 15) assumes that the monetary policy rule is $i_{t}=\pi_{t}+\rho+\theta_{\pi}\left(\pi_{t}-\pi^{*}\right)+\theta_{Y}\left(Y_{t}-\bar{Y}_{t}\right)$, where the central bank's inflation target $\left(\pi^{*}\right)$ and its policy parameters $\theta_{\pi}$ and $\theta_{Y}$ are all non-negative. We, however, wish to explicitly incorporate the fact that nominal interest rates need to be non-negative. Therefore, our generalized monetary policy rule is:

$$
i_{t}=\max \left\{0, \pi_{t}+\rho+\theta_{\pi} \cdot\left(\pi_{t}-\pi^{*}\right)+\theta_{Y} \cdot\left(Y_{t}-\bar{Y}_{t}\right)\right\}
$$

Equations (1)-(5) describe our DAD-DAS model. For given values of the model's period- $t$ parameters $\left(\alpha, \rho, \phi, \theta_{\pi}, \theta_{Y}, \pi^{*}\right.$, and $\left.\bar{Y}_{t}\right)$, its period- $t$ shocks $\left(\epsilon_{t}\right.$ and $\left.\nu_{t}\right)$, and the pre-determined inflation rate $\left(E_{t-1} \pi_{t}=\pi_{t-1}\right)$ for period $t-1$, one can use the the model's five equations to solve for its five period- $t$ endogenous variables $\left(Y_{t}, r_{t}, i_{t}, E_{t} \pi_{t+1}\right.$, and $\left.\pi_{t}\right)$. Once it is understood that the inherited inflation rate $\left(\pi_{t-1}\right.$, which is also previous period's equilibrium inflation rate) determines the current equilibrium inflation rate, one sees the dynamics that are internal to the DAD-DAS model. Parameter changes and/or shocks are not the only source of change; what happened yesterday determines what happens today which will determine what happens tomorrow, and so on. ${ }^{2}$

For the graphical treatment of the model, we will - following Mankiw - turn our five equations that contain five endogenous variables into two equations that contain two endogenous variables, $Y_{t}$ and $\pi_{t}$. The two equations will then be graphed as the dynamic aggregate demand (DAD) and dynamic aggregate supply (DAS) curves, with $Y_{t}$ on the 
horizontal axis and $\pi_{t}$ on the vertical axis. The intersection of the two curves will determine the equilibrium values $Y_{t}$ and $\pi_{t}$.

\subsection{The Kinked $D A D$ Curve}

Here we introduce the only element of the DAD-DAS model of (Mankiw, 2013, Ch. 15) that changes when the zero lower bound (ZLB) on the nominal interest rate is added. To give away the punchline, Mankiw's negatively-sloped DAD curve becomes a kinked DAD curve with a negatively-sloped segment (when the ZLB is non-binding) and a positivelysloped segment (when the ZLB is binding).

Figure 1 shows, among other things, the border that separates the $\left(Y_{t}, \pi_{t}\right)$-outcomes for which the ZLB is not binding from the $\left(Y_{t}, \pi_{t}\right)$-outcomes for which the ZLB is binding. Algebraically, the monetary policy rule (5) implies that this border satisfies

$$
\pi_{t}+\rho+\theta_{\pi} \cdot\left(\pi_{t}-\pi^{*}\right)+\theta_{Y} \cdot\left(Y_{t}-\bar{Y}_{t}\right)=0
$$

Above this border, the ZLB is not binding and the nominal interest rate set by the central bank is positive $\left(i_{t}>0\right)$; Mankiw's analysis applies to this case word for word. On the border, the central bank chooses a zero interest rate, but does so willingly, and not because it wanted a negative rate but could not choose it because of the ZLB. Below the border, the ZLB is binding $\left(i_{t}=0\right) .^{3}$

[Figure 1 about here.]

Mankiw (2013, Ch. 15) derives the equation of his DAD curve as follows: substitute adaptive expectations (4) and Mankiw's simplified monetary policy rule $\left(i_{t}=\pi_{t}+\rho+\theta_{\pi}\right.$. $\left.\left(\pi_{t}-\pi^{*}\right)+\theta_{Y} \cdot\left(Y_{t}-\bar{Y}_{t}\right)\right)$ into the Fisher equation (2), substitute the resulting expression for the real interest rate in the IS equation (1), and rearrange and collect the terms. In this way, Mankiw gets

$$
Y_{t}=\bar{Y}_{t}-\frac{\alpha \theta_{\pi}}{1+\alpha \theta_{Y}}\left(\pi_{t}-\pi^{*}\right)+\frac{1}{1+\alpha \theta_{Y}} \epsilon_{t}
$$

This is graphed as the negatively-sloped line in the section of Figure 1 where the ZLB is not binding. 
The DAD curve in Figure 1 assumes that the demand shock is absent $\left(\epsilon_{t}=0\right)$. Consequently, $\pi_{t}=\pi^{*}$ and $Y_{t}=\bar{Y}_{t}$ satisfies equation (7). This is point $O$ in Figure 1 ; it will play an important role in our discussion of the model's equilibrium below.

Note that equation (7) implies that Mankiw's DAD curve-i.e., the DAD curve when the ZLB is not binding - shifts rightward under both expansionary monetary policy $\left(\pi^{*} \uparrow\right)$ and expansionary fiscal policy $\left(\epsilon_{t} \uparrow\right)$. This is shown in Figures 2 and 3 .

[Figure 2 about here.]

[Figure 3 about here.]

Repeating Mankiw's procedure, but with $i_{t}=0$, we get the DAD curve for the case in which the ZLB is binding:

$$
Y_{t}=\bar{Y}_{t}+\alpha \cdot\left(\pi_{t}+\rho\right)+\epsilon_{t}
$$

Note that the slope is positive $\left(d \pi_{t} / d Y_{t}=1 / \alpha>0\right)$, which is why the DAD curve in Figure 1 turns into a positively-sloped line below the ZLB border. The familiar negativelysloped DAD curve we see in textbooks becomes a kinked curve when the analysis allows the ZLB to be binding. Algebra aside, the positively-sloped segment is meant to capture the idea that falling inflation is a special nightmare at the zero lower bound. As $i_{t}=0$, any decline in current inflation $\left(\pi_{t} \downarrow\right)$ means an increase in the current real interest rate $\left(r_{t}=i_{t}-E_{t} \pi_{t+1}=i_{t}-\pi_{t}=0-\pi_{t}=-\pi_{t} \uparrow\right)$. The rising real interest rate reduces aggregate demand and output $\left(Y_{t} \downarrow\right)$, as the familiar IS curve (1) dictates. ${ }^{4}$

By contrast, when the ZLB is not binding, the negatively-sloped DAD curve reflects a different story. Any decrease in inflation provokes the monetary policy rule (5) to reduce the nominal interest rate even more, as dictated by the Taylor principle. As a result, the real interest rate falls, thereby causing both aggregate demand and output to increase.

To finish our discussion of the rising segment of the DAD curve, when $\epsilon_{t}=0$, note that $\pi_{t}=-\rho$ and $Y_{t}=\bar{Y}_{t}$ satisfy equation (8). This is point $D$ in Figure 1 ; like point $O$, $D$ too will play an important role in our discussion of the model's equilibrium.

Equation (8) also implies that the positively-sloped segment of the DAD curve shifts rightward under expansionary fiscal policy $\left(\epsilon_{t} \uparrow\right)$ and is extended but not shifted by expansionary monetary policy. This is shown in Figures 2 and 3. 


\subsection{The $D A S$ Curve}

When adaptive expectations (4) is substituted into the Phillips curve (3), we get Mankiw's dynamic aggregate supply or DAS curve:

$$
\pi_{t}=\pi_{t-1}+\phi \cdot\left(Y_{t}-\bar{Y}_{t}\right)+\nu_{t}
$$

It follows from equation (9) that the slope of the DAS curve is $d \pi_{t} / d Y_{t}=\phi>0$, as shown in Figure 4. It also follows that any change in the pre-determined inherited rate of inflation $\left(\pi_{t-1}\right)$, or in the supply shock $\left(\nu_{t}\right)$, or indeed in $\pi_{t-1}+\nu_{t}$, leads to an equal change in the height of the DAS curve. The link between $\pi_{t-1}$ and $\pi_{t}$ in the DAS equation (9) is the only source of dynamics in the DAD-DAS model; note that the DAD equations (7) and (8) contain only period- $t$ variables.

Finally, note that, when the supply shock is assumed absent $\left(\nu_{t}=0\right.$; as in the DAS curves $D A S_{O}, D A S_{R}$, and $D A S_{D}$ in Figure 4), $Y_{t}=\bar{Y}$ and $\pi_{t}=\pi_{t-1}$ satisfy equation (9). This is the case for the outcomes $O, R^{\prime}$, and $D$ in Figure 4 .

Now that we have discussed the DAS and DAD curves, we are ready to bring them together to discuss equilibrium.

[Figure 4 about here.]

\section{Long-Run Equilibria}

Equilibrium at any period $t$ is graphically represented by the intersection of the DAD and DAS curves for period $t$. Figure 5 shows three such equilibria-at $O, R$, and $D$-for the same DAD curve and three different DAS curves.

Let us begin with the equilibrium at $R$. As can be confirmed by a quick glance at the DAS equation (9), as $Y_{t}>\bar{Y}$ at $R$ and as $\nu_{t}=0$ has been assumed, it must be that $\pi_{t}>\pi_{t-1}$. That is, inflation is rising over time. Therefore, this cannot be what Mankiw calls a long-run equilibrium, which is an equilibrium outcome that repeats itself (as long as the model's parameters stay unchanged and there are no shocks). As a general matter, if no restrictions are imposed on the DAD-DAS model's parameters and shocks, there is no reason to expect an equilibrium outcome to repeat itself period after period. The 
question then is the following: do there exist restrictions on the model's parameters and shocks under which an equilibrium outcome would repeat itself over and over again?

Let us now look at the equilibrium at $O$ in Figure 5. In this case, $\pi_{t}=\pi_{t-1}=\pi^{*}$ and $Y_{t}=\bar{Y}$. With no parameter changes and no shocks, the DAD curve at $t+1$ will be identical to the DAD curve at $t$, which is the one shown in Figure 5. And, as inherited inflation is the same in periods $t$ and $t+1\left(\pi_{t-1}=\pi_{t}=\pi^{*}\right)$ and $\nu_{t}=\nu_{t+1}=0$ by assumption, the DAS curve at $t+1$ will be identical to the DAS curve at $t$, which is $D A S_{O}$ of Figure 5. Therefore, $O$ represents the equilibrium outcome for periods $t+1$ as well as $t$. In short, we have found an equilibrium that repeats. We can conclude that (a) if the DAD-DAS model's parameters stay constant, (b) if the two shocks stay at zero $\left(\epsilon_{t}=\nu_{t}=0\right)$, and (c) if the inherited inflation happens to be equal to the central bank's target inflation $\left(\pi_{t-1}=\pi^{*}\right)$, then the equilibrium outcome would continue unchanged forever.

[Figure 5 about here.]

Mankiw goes on to show, algebraically and graphically, that the equilibrium at $O$ in Figure 5-which we will henceforth refer to as the orthodox equilibrium - is the one and only long-run equilibrium of his DAD-DAS model (which, recall, makes no mention of the ZLB). To fully describe the orthodox equlibrium, note that the monetary policy rule (5) implies $i_{t}=\pi^{*}+\rho$, and the Fisher equation (2) and adaptive expectations (4) imply $r_{t}=i_{t}-E_{t} \pi_{t+1}=i_{t}-\pi_{t}=\rho$.

With the introduction of the ZLB, however, we now have a kinked DAD curve with a new positively-sloped segment, and it is straightforward to check that outcome $D$ in Figure 1, at the intersection of the kinked $D A D$ curve and $D A S_{D}$, is also a long-run equilibrium. Although output is $\bar{Y}$ and the real interest rate is $\rho$, exactly as in Mankiw's orthodox equilibrium, the nominal interest rate is zero - we are at the zero lower bound, after all - and the inflation rate is $-\rho<0$. We call $D$ the deflationary equilibrium.

Before we move on to our discussion of the stability of our two long-run equilibria, a technical issue needs to be discussed. Note that $D A S_{D}$ in Figure 5 is drawn flatter than the rising part of the DAD curve. This reflects our assumption that $1 / \alpha$, which is 
the slope of the ZLB section of the DAD curve, exceeds $\phi$, the slope of the DAS curve. Equivalently, we assume $1-\alpha \phi>0$. We discuss this assumption further in section 4.1.

\section{Stability of Long-Run Equilibria}

We will now show that not only does the ZLB add a new long-run equilibrium - the deflationary equilibrium - to the DAD-DAS model, the deflationary equilibrium is unstable, unlike the orthodox equilibrium, which is stable.

Let us assume that the parameters of the DAD-DAS model $\left(\alpha, \phi, \rho, \theta_{Y}, \theta_{\pi}, \pi^{*}\right.$, and $\bar{Y})$ are constant - and both shocks are at zero - from period $t$ onwards. Under these conditions, we saw in section 3 that if $\pi_{t-1}=\pi^{*}$ the economy will stay at the othodox equilibrium forever, and if $\pi_{t-1}=-\rho$ the economy will stay at the deflationary equilibrium forever. But what if $\pi_{t-1}$ is neither $\pi^{*}$ nor $-\rho$ ? For arbitrary values of $\pi_{t-1}$, how will the economy behave during periods $t$ and later?

Under our assumption that the parameters $\left(\alpha, \phi, \rho, \theta_{Y}, \theta_{\pi}, \pi^{*}\right.$, and $\left.\bar{Y}\right)$ are constantand both shocks are at zero - from period $t$ onwards, the kinked $D A D$ curve will be the same for all periods $t$ and later. Let this $D A D$ curve be the one shown in Figure 6 .

[Figure 6 about here.]

Case 1: $\pi_{t-1}>\pi^{*}$. Let $\pi_{t-1}=\pi_{Q}>\pi^{*}$. As $\pi_{t-1}>\pi^{*}$, the $D A S$ curve at period $t$, indicated in Figure 6 by $D A D_{Q}$, must be higher than $D A S_{O}$, for which inherited inflation was specified to be $\pi_{t-1}=\pi^{*}$. As we saw in section 2.2 , the height of $D A D_{Q}$ at $Y_{t}=\bar{Y}$ is $\pi_{t-1}=\pi_{Q}>\pi^{*}$, as shown in Figure 6. The equilibrium at period $t$ is, therefore, at $q$, with $\pi_{t-1}>\pi_{t}>\pi^{*}$. In other words, if inherited inflation exceeds $\pi^{*}$, current inflation will be lower than inherited inflation while still remaining higher than $\pi^{*}$. Applying this result recursively while keeping in mind that this period's current inflation is next period's inherited inflation, we see that inflation will converge to $\pi^{*}$ and the equilibrium outcome will converge to the orthodox equilibrium. ${ }^{5}$

Case 2: $-\rho<\pi_{t-1}<\pi^{*}$. Let $-\rho<\pi_{t-1}=\pi_{R}<\pi^{*}$. Therefore, the DAS curve at $t$ will be somewhere between $D A S_{O}$ and $D A S_{D}$, for which inherited inflation was specified to be $\pi_{t-1}=\pi^{*}$ and $\pi_{t-1}=-\rho$ respectively. Let this DAS curve be $D A S_{R}$ in Figure 6 . 
The period- $t$ equilibrium is, therefore, at $r$ with $-\rho<\pi_{t-1}<\pi_{t}<\pi^{*}$. In other words, if inherited inflation lies between $-\rho$ and $\pi^{*}$, current inflation will be higher than inherited inflation while still remaining between $-\rho$ and $\pi^{*}$. Applying this result recursively while keeping in mind that this period's current inflation is next period's inherited inflation, we see that the equilibrium outcome will converge to the orthodox equilibrium.

Case 3: $-\rho>\pi_{t-1}$. Let $\pi_{t-1}=\pi_{U}<-\rho$. The DAS curve at $t$ will be below $D A S_{D}$. Let this DAS curve be $D A S_{U}$ in Figure 6. The equilibrium will be at $u$ with $\pi_{t}<\pi_{t-1}<-\rho$. In other words, if inherited inflation is less than $-\rho$, current inflation will be lower than inherited inflation and therefore even farther below $-\rho$. Applying this result recursively while keeping in mind that this period's current inflation is next period's inherited inflation, we see that the equilibrium outcome will diverge from the deflationary equilibrium with both inflation and output falling continuously. This is the much dreaded deflationary spiral. ${ }^{6}$

To sum up, we have shown that as long as the parameters of the DAD-DAS model do not change and there are no shocks, the economy will either converge to the orthodox equilibrium or be in the ever worsening deflationary spiral. The key knife's edge factor is the inflation rate. If inflation falls below $-\rho$, which is the negative of the natural real interest rate, the economy's fate is the deflationary spiral with ever decreasing inflation and output. If the inflation rate stays above $-\rho$, there is no reason to worry.

\subsection{On the Slopes of the DAD and DAS Curves}

Recall that in our discussion above we have assumed that $\phi$, the slope of the DAS curve, is smaller than $1 / \alpha$, the slope of the positively-sloped segment of the DAD curve (under the ZLB). We will now argue that this assumption is necessary to avoid comparative static results that seem unrealistic to us.

Consider the equilibrium outcome $a$ at the intersection of $D A S$ and $D A D_{1}$ in the left panel of Figure 7. Note that, contrary to our assumption above, DAS has been drawn steeper than $D A D_{1}$. Now consider a positive demand shock $\left(\epsilon_{t} \uparrow\right)$. As we saw in section 2.1 and Figure 2, the economy's DAD curve will shift rightward to, say, $D A D_{2}$. Therefore, the new equilibrium will be at $b$. In other words, an increase in demand leads to lower 
inflation and output. This outcome strikes us as unrealistic.

Similarly, in the right panel of Figure 7, we see another comparative static result that seems unrealistic to us: an increase in the cost shock $\left(\nu_{t} \uparrow\right)$ such as increases in the price of imported oil or a series of bad droughts leads to lower inflation.

These unrealistic comparative static results can be avoided by assuming $1 / \alpha>\phi$ or, equivalently, $1-\alpha \phi>0$.

[Figure 7 about here.]

\section{$5 \quad$ Policy Responses to Deflationary Spirals}

Given that a deflationary spiral — with output decreasing without bound - is undesirable, (i) what can be done to keep an economy away from it, and (ii) what can be done to get an economy out of a deflationary spiral if it is already in one? We will show that expansionary fiscal policy - that is, an increase in $\epsilon_{t}$ in the goods market's equilibrium condition (1) - is an adequate answer to both questions, and expansionary monetary policy - that is, an increase in the central bank's target inflation rate $\left(\pi^{*}\right)$ in the monetary policy rule (5) - is a partial answer to (i).

\subsection{Fiscal Stimulus Works}

Recall that Figure 2 shows how expansionary fiscal policy $\left(\epsilon_{t}>0\right)$ shifts our kinked $D A D$ curve to the right. This is reproduced in Figure 8.

Suppose inflation has fallen below $-\rho$ and, consequently, the economy has already fallen into a deflationary spiral. ${ }^{7}$ Suppose the $D A S$ curve is expected to be at $D A S_{U}$ in period $t$. In that case, if there is no government intervention the period $t$ equilibrium will be at $u$ in Figure 8. However, as in the figure, expansionary fiscal policy in period $t$ can move the equilibrium to $v$, thereby lifting the inflation rate above $-\rho$. Once that is achieved, the fiscal stimulus can be withdrawn (i.e., $\epsilon_{t}$ can return to zero and DAD can return to its original position) and, as we have seen before, the economy will gradually converge to the orthodox equilibrium. 
The same policy can also be used as a prophylactic. If, for some reason, it is imminent that the $D A S$ curve will drop to $D A S_{U}$, we can use expansionary fiscal policy to shift the DAD curve to the right, thereby nipping the deflationary spiral in the bud.

Finally, if inflation has been - or soon will be - pushed below - $\rho$ by a leftward shift in the $D A D$ curve - say, by a decline in 'animal spirits' or 'confidence' - then, it goes without saying, expansionary fiscal policy can negate such a leftward shift.

[Figure 8 about here.]

\subsection{Expansionary Monetary Policy May Work}

Recall that Figure 3 shows how expansionary monetary policy $\left(\pi^{*} \uparrow\right)$ shifts our kinked $D A D$ curve. This is reproduced in Figure 9.

Suppose the economy is at $u$ in Figure 9, inflation has dropped below $-\rho$, and, therefore, a deflationary spiral is already underway. Expansionary monetary policy - which can only extend the positively-sloped segment of the DAD curve but not shift it - is of no use in this case. A deflationary spiral can only occur when the zero lower bound on the nominal interest rate is binding. As a result, monetary policy is ineffective in a deflationary spiral.

Similarly, if the ZLB is binding — say, the economy is at $v$ in Figure 9 on the positivelysloped part of the $D A D$ curve - monetary policy would not be able to counteract an imminent decline in the $D A S$ curve to $D A S_{U}$ that would initate a deflationary spiral.

However, suppose the economy is at $x$ in Figure 9 and an imminent decrease in the suply shock is expected to take the economy to $u$. This threatens to reduce the inflation rate to $-\rho-\delta$ and thereby initiate a deflationary spiral. In this case, because the ZLB is non-binding at $x$, expansionary monetary policy $\left(\pi^{*} \uparrow\right)$ can raise the equilibrium inflation rate by $\Delta$, as a comparison of points $x$ and $y$ shows. And if $\Delta>\delta$, this would be enough to keep the equilibrium inflation rate above $-\rho$ and thereby prevent a deflationary spiral.

To sum up, in the DAD-DAS model, expansionary fiscal policy can be used to rescue an economy that is already in a deflationary spiral and, pre-emptively, to stop an imminent deflationary spiral. Expansionary monetary policy cannot help if a deflationary spiral is 
already underway. It may help to keep an economy out of a deflationary spiral, but only if the zero lower bound on the nominal interest rate has not become binding.

[Figure 9 about here.]

\section{The Zero Lower Bound in Prominent Textbooks}

We have shown how the graphical DAD-DAS model in Mankiw (2013) can be easily modified to include the zero lower bound on the nominal interest rate. We have also shown that the ZLB gives us a deflationary long-run equilibrium and a deflationary spiral. In this section, we will discuss the treatment of these issues in four other intermediate macroeconomics textbooks: Blanchard and Johnson (2013), Carlin and Soskice (2006), Jones (2011), and Mishkin (2011).

These four textbooks all discuss the zero lower bound and they all make the point that expansionary fiscal policy works at the ZLB whereas expansionary monetary policy - at least of the conventional kind - does not. The five equations of Mankiw's DAD-DAS model-(1)-(5) - are present in all four textbooks. However, these five equations are scattered across multiple chapters and are not analyzed together-either graphically or algebraically — as a unified model.

Using monetary policy rules that are somewhat different from Mankiw's rule (5), Carlin and Soskice (2006), Jones (2011), and Mishkin (2011) present graphical models that, like Mankiw (2013), determine both output and inflation at the intersection of a negatively-sloped demand curve and a positively-sloped supply curve. And, like Mankiw (2013), they do not discuss how the ZLB affects their graphs. When we add the ZLB to the models in Carlin and Soskice (2006), Jones (2011), and Mishkin (2011), we again get kinked demand curves. For Carlin and Soskice (2006) and Jones (2011), this kinked demand curve has a positively-sloped segment for inflation rates below a critical level, as in our modification of Mankiw (2013). For Mishkin (2011) we again get a kink, but with a vertical segment instead of a positively-sloped segment.

Why the difference? In both Carlin and Soskice (2006) and Jones (2011), the Fisher equation and adaptive expectations yield the usual result that the current real interest 
rate equals the current nominal interest rate less the current inflation rate: $r_{t}=i_{t}-$ $\pi_{t}$. Therefore, at the ZLB, $r_{t}=-\pi_{t}$. As a result, lower current inflation leads to a higher current real interest rate, which, by the IS curve, leads to lower current output, thus yielding a positively-sloped demand curve. In Mishkin (2011), however, the Fisher equation is expressed as $r=i-\pi^{e}$ and adaptive expectation is expressed as $\pi^{e}=\pi_{-1}$, which is inherited inflation. Therefore, the current real interest rate $\left(r=i-\pi_{-1}\right)$ is unaffected by current inflation $(\pi)$. Lower current inflation has no effect on current real interest rate and, therefore, no effect on current output, thus yielding a vertical demand curve below the kink.

It seems natural to us to think that when the nominal interest rate is stuck at zero, lower inflation will lead to higher real interest rates and, therefore, to lower output. However, this persuasive 'story' of an economy at the ZLB does not follow from Mishkin's treatment because of the seemingly minor difference in his treatment of the Fisher equation.

Although none of the four textbooks describe our deflationary long-run equilibrium, the textbooks by Carlin and Soskice (2006) and Jones (2011) are distinctive because they provide somewhat informal but intuitive accounts of the deflationary spiral. They explain the deflationary spiral as follows: Suppose $\rho$ is the real interest rate consistent with full employment. If $\pi<-\rho$, then $i=r+\pi \geq 0$ implies $r \geq-\pi>\rho$. Therefore, full employment would not be possible. The resulting recession would drive inflation farther below $-\rho$, and so on and on, causing a deflationary spiral. While this explanation is intuitive, it is not complete - in our view-because current inflation is an endogenous variable and it is simultaneously determined along with current output, the current real interest rate, and the current nominal interest rate. It is necessary to explain why $\pi<-\rho$ would occur in the first place.

Our analysis shows that if inherited inflation, which is a pre-determined variable, reaches $\pi_{t-1}<-\rho$, then a deflationary spiral occurs. To repeat, it is necessary to express the conditions that lead to a deflationary spiral entirely interms of the model's exogenous givens.

Blanchard and Johnson (2013) presents a graphical model that determines current 
output and the current price level at the intersection of a negatively-sloped demand curve and a positively-sloped supply curve. Unlike the other textbooks, Blanchard and Johnson (2013, Fig. 9-10, page 199) also show how their demand curve looks under the ZLB: it is kinked, but with a vertical, rather than positively-sloped, segment for current inflation rates below a critical level at which the ZLB is binding. Blanchard and Johnson (2013, Page 296) also provides an informal but valuable explanation of the deflationary spiral through an examination of the U.S. economy during the Great Depression.

To summarize, although all five textbooks considered here take note of the ZLB, none describes our deflationary long-run equilibrium, and none describes the conditions - in terms of the exogenous variables and parameters of the model economy - under which a deflationary spiral occurs. None of these textbooks describe how the ZLB changes the graphical determination of output and inflation. We have tried to argue that a simple modification of the demand curve addresses all these issues.

\section{Conclusion}

Several of today's leading textbooks for intermediate macroeconomics courses include a dynamic New Keynesian model of short-run macroeconomics consisting of an IS curve, a Phillips curve, and a monetary policy rule. In this paper, we have shown that when the DAD-DAS model in Mankiw (2013) is generalized to incorporate the zero lower bound on the nominal interest rate, it has two long-run equilibria, one stable and the other unstable. We have demonstrated the existence of a deflationary spiral in which both output and inflation fall without bound. We have also described policy responses that can keep an economy out of the deflationary spiral and/or rescue it from such a spiral in case one has already begun.

We realize that a deflationary spiral in which output falls without bound is unrealistic. In Blanchard and Johnson (2013, "Deflation and the Phillips Curve Relation", page 178) the authors point out that during the Great Depression inflation was systematically higher in the U.S. than predicted by the estimated (or, fitted) Phillips curve. Based on this observation, they argue persuasively that workers are reluctant to accept decreases in their nominal wages and that the Phillips curve relation breaks down at low levels of 
inflation. Adapting this paper's model to deal comprehensively with the deflationary spiral remains a topic for future research.

For the time being, note that monetary policy in the United States and Japan-to take just two examples - has been stuck at the zero lower bound since 2008 and 1995, respectively. Students need to see how short-run macroeconomics works under these no longer new - and no longer unusual - circumstances. 


\section{Notes}

${ }^{1}$ For the graphical analysis in the rest of the paper, we will make the simplifying assumption $\bar{Y}_{t}=\bar{Y}$ for all $t$.

${ }^{2}$ While the algebra of these dynamics are worked out in the appendix, the body of the paper presents a graphical treatment similar in style to a typical intermediate macroeconomics textbook.

${ }^{3}$ Note, from (6), that expansionary monetary policy $\left(\pi^{*} \uparrow\right)$ moves the border upwards and to the right - thereby expanding the region where the ZLB is binding - whereas expansionary fiscal policy $\left(\epsilon_{t} \uparrow\right)$ has no effect.

${ }^{4}$ The negative feedback loop between output and inflation is the mechanism that leads to a deflation-induced depression, as previously explained by Fisher (1933) and Krugman (1998). In normal times, when nominal interest rates are positive, the central bank can afford to cut interest rates following a negative demand shock to provide short-run stimulus to the economy. When the zero-lower bound is binding, however, cutting rates is not feasible and real interest rates spike up as a result of lower inflation. Higher real rates in turn depress the economy further, which put further pressure on real rates, which depress the economy further, and so on and so forth.

${ }^{5}$ Algebraic proofs of the stability results of this section are given in the appendix.

${ }^{6}$ Note that the good news of a favorable cost shock $\left(\nu_{t} \downarrow\right)$ - such as a fall in the price of imported oil - can trigger a deflationary spiral by lowering the DAS curve, say, from $D A S_{D}$ to $D A S_{U}$. This point has been underscored by Carlstrom and Pescatori (2009): "[T]o be effective in an environment of zero short-term nominal interest rates, monetary policy needs to be unequivocally committed to avoiding expectations of deflation. ... While this policy prescription follows from the assumption that the zero interest rate bound is a consequence of a negative demand shock hitting the economy, it is worth stressing that falling prices can also be the consequence of a supply shock, namely particularly high productivity growth (not a bad thing!)." 
${ }^{7}$ See the discussion in section 4 . 


\section{References}

Olivier Blanchard and David R. Johnson. Macroeconomics. Prentice Hall, $6^{\text {th }}$ edition, 2013.

Wendy Carlin and David Soskice. Macroeconomics: Imperfections, Institutions, and Policies. Oxford University Press, 2006.

Charles T. Carlstrom and Andrea Pescatori. Conducting monetary policy when interest rates are near zero, December 2009. URL http://www.clevelandfed.org/research/ commentary/2009/1009.cfm.

Irving Fisher. The debt-deflation theory of great depressions. Econometrica, 1(4):337-357, 1933.

Charles I. Jones. Macroeconomics. W.W. Norton, $2^{\text {nd }}$ edition, 2011.

Paul Krugman. It's Baack! Japan's Slump and the Return of the Liquidity Trap. Brookings Papers on Economic Activity, 29(2):137-187, 1998.

Gregory N. Mankiw. Macroeconomics. Worth Publishers, eighth edition, 2013.

Frederic S. Mishkin. Macroeconomics: Policy and Practice. Prentice Hall, $1^{\text {st }}$ edition, 2011.

John B. Taylor. Discretion versus policy rules in practice. Carnegie-Rochester Conference Series on Public Policy, 39:195-214, 1993. 


\section{Appendix: An Algebraic Representation of the Model}

Mankiw (2013, Ch. 15) presents numerical simulations of the dynamic adjustment of the DAD-DAS model's economy to various shocks and policy changes. This requires that the equilibrium values of the model's endogenous variables be expressed in terms of the model's parameters, shocks, and the pre-determined value of inherited inflation. In this appendix, we complete this algebraic task.

\subsection{When the Zero Lower Bound is Not Binding}

In this section, we assume that the ZLB is not binding. Later in this section we will specify the conditions - in terms of the model's parameters, shocks, and the pre-determined value of inherited inflation - under which the ZLB is not binding.

We have seen the derivation of the DAD curve (7) and the DAS curve (9). The former yields

$$
Y_{t}-\bar{Y}_{t}=-\frac{\alpha \theta_{\pi}}{1+\alpha \theta_{Y}}\left(\pi_{t}-\pi^{*}\right)+\frac{1}{1+\alpha \theta_{Y}} \epsilon_{t}
$$

By substituting this for $Y_{t}-\bar{Y}_{t}$ in (9), rearranging and collecting the terms, we get the short-run equilibrium inflation:

$$
\pi_{t}=\frac{\left(1+\alpha \theta_{Y}\right)\left(\pi_{t-1}+\nu_{t}\right)+\phi \cdot\left(\alpha \theta_{\pi} \pi^{*}+\epsilon_{t}\right)}{1+\alpha \theta_{Y}+\alpha \theta_{\pi} \phi} .
$$

Note that equation (10) is simulation-ready. By substituting numerical values for the model's parameters, shocks, and the pre-determined value of inherited inflation we can calculate the numerical value of the current period's inflation. And as this period's current inflation is next period's inherited inflation, the exercise can be repeated ad infinitum. Note also that current inflation is increasing in inherited inflation, the cost shock and the demand shock, as one would expect.

By substituting (10) into the DAD curve (7), we get the short-run equilibrium output:

$$
Y_{t}=\bar{Y}_{t}+\frac{\alpha \theta_{\pi}\left(\pi^{*}-\pi_{t-1}-\nu_{t}\right)+\epsilon_{t}}{1+\alpha\left(\theta_{\pi} \phi+\theta_{Y}\right)}
$$

Note that output increases under expansionary monetary policy $\left(\pi^{*} \uparrow\right)$ and/or expansionary fiscal policy $\left(\epsilon_{t} \uparrow\right)$. 
By substituting (11) into Mankiw's simplified monetary policy rule $\left(i_{t}=\pi_{t}+\rho+\theta_{\pi}\right.$. $\left.\left(\pi_{t}-\pi^{*}\right)+\theta_{Y} \cdot\left(Y_{t}-\bar{Y}_{t}\right)\right)$, we get the short-run equilibrium nominal interest rate:

$$
i_{t}=\rho+\frac{\left(1+\theta_{\pi}+\alpha \theta_{Y}\right)\left(\pi_{t-1}+\nu_{t}\right)-(1-\alpha \phi) \theta_{\pi} \pi^{*}+\left(\theta_{Y}+\left(1+\theta_{\pi}\right) \phi\right) \epsilon_{t}}{1+\alpha \cdot\left(\theta_{\pi} \phi+\theta_{Y}\right)} .
$$

Equations (2) and (4) together imply that the real interest rate is $r_{t}=i_{t}-E_{t} \pi_{t+1}=$ $i_{t}-\pi_{t}$. By substituting equations (12) and (10), we get

$$
r_{t}=\rho+\frac{\theta_{\pi}\left(\pi_{t-1}+\nu_{t}-\pi^{*}\right)+\left(\theta_{Y}+\theta_{\pi} \phi\right) \epsilon_{t}}{1+\alpha \theta_{Y}+\alpha \theta_{\pi} \phi} .
$$

Equation (12) can now be used to derive the conditions under which the ZLB is binding or not. Let $\pi_{t-1}^{c}$ be that rate of inherited inflation $\left(\pi_{t-1}\right)$ for which $i_{t}=0$ in equation (12). By equating the right-hand side of equation (12) to zero and rearranging the terms we get

$$
\pi_{t-1}^{c} \equiv \frac{(1-\alpha \phi) \theta_{\pi} \pi^{*}-\left(1+\alpha \theta_{\pi} \phi+\alpha \theta_{Y}\right) \rho-\left(\theta_{\pi} \phi+\theta_{Y}+\phi\right) \epsilon_{t}}{1+\theta_{\pi}+\alpha \theta_{Y}}-\nu_{t}
$$

We already know by definition that that (a) $i_{t}=0$ when $\pi_{t-1}=\pi_{t-1}^{c}$. As equation (12) implies that the nominal interest rate is strictly increasing in the inherited inflation rate $\left(\partial i_{t} / \partial \pi_{t-1}>0\right)$, it follows further that (b) $i_{t}>0$ when $\pi_{t-1}>\pi_{t-1}^{c}$, and (c) $i_{t}<0$ when $\pi_{t-1}<\pi_{t-1}^{c}$. But we know from (5) that the nominal interest rate cannot be negative. Therefore, we conclude that the ZLB is binding if and only if $\pi_{t-1}<\pi_{t-1}^{c}$. Therefore, the expressions for inflation, output, and the interest rates derived above are valid only when $\pi_{t-1} \geq \pi_{t-1}^{c}$.

Returning to the equilibrium inflation rate (10) above, it can be checked that if $\epsilon_{t}=$ $\nu_{t}=0$ and $\pi_{t-1}=\pi^{*}$ are substituted in equation (10), we get $\pi_{t-1}=\pi_{t}=\pi^{*}$. In other words, when there are no shocks, if the inherited inflation is equal to the central bank's target inflation then the inflation rate repeats itself ad infinitum. This is the orthodox long-run equilibrium of section 3 .

By substituting $\epsilon_{t}=\nu_{t}=0$ and $\pi_{t-1}=\pi_{t}=\pi^{*}$ into equations (11), (12), and (13) above, it is straightforward to show that in the orthodox long-run equilibrium output is $\bar{Y}_{t}$, the nominal interest rate is $\rho+\pi^{*}$, and the real interest rate is $\rho$.

The stability of the orthodox long-run equilibrium can now be proved. If we subtract $\pi^{*}$ from both sides of equation (10) and rearrange and collect the terms, we get

$$
\pi_{t}-\pi^{*}=\frac{\left.\left(1+\alpha \theta_{Y}\right)\left(\pi_{t-1}-\pi^{*}+\nu_{t}\right)+\phi \epsilon_{t}\right)}{1+\alpha \theta_{Y}+\alpha \theta_{\pi} \phi} .
$$


When there are no shocks $\left(\epsilon_{t}=\nu_{t}=0\right)$, this becomes

$$
\pi_{t}-\pi^{*}=\frac{1+\alpha \theta_{Y}}{1+\alpha \theta_{Y}+\alpha \theta_{\pi} \phi} \cdot\left(\pi_{t-1}-\pi^{*}\right) .
$$

As $0<\left(1+\alpha \theta_{Y}\right) /\left(1+\alpha \theta_{Y}+\alpha \theta_{\pi} \phi\right)<1$, it follows that the gap between inflation and the central bank's target inflation retains its sign and shrinks over time (as long as there are no shocks and the model's parameters stay constant). In other words, if the ZLB is non-binding $\left(\pi_{t-1} \geq \pi_{t-1}^{c}\right)$, the inflation rate $\left(\pi_{t}\right)$ converges monotonically to the orthodox long-run equilibrium inflation rate $\left(\pi^{*}\right)$.

It is then straightforward, using equations (11), (12), and (13), that output and the interest rates also converge to their respective orthodox long-run values.

\subsection{When the Zero Lower Bound is Binding}

We now assume that the ZLB is binding $\left(\pi_{t-1}<\pi_{t-1}^{c}\right)$. In this case, the nominal interest rate set by the central bank is $i_{t}=0$. Easy!

We have seen the derivation of the DAD curve (8) and the DAS curve (9). The former yields $Y_{t}-\bar{Y}_{t}=\alpha \cdot\left(\pi_{t}+\rho\right)+\epsilon_{t}$. By substituting this expression for $Y_{t}-\bar{Y}_{t}$ into (9), rearranging and collecting the terms, we get the short-run equilibrium inflation rate:

$$
\pi_{t}=\frac{\pi_{t-1}+\nu_{t}+\phi \alpha \rho+\phi \epsilon_{t}}{1-\alpha \phi}
$$

Simulation-ready expressions for the real interest rate and output can be derived by substituting equation (15) into $r_{t}=i_{t}-E_{t} \pi_{t+1}=i_{t}-\pi_{t}=0-\pi_{t}=-\pi_{t}$ and (8).

It can be checked that if $\epsilon_{t}=\nu_{t}=0$ and $\pi_{t-1}=-\rho$ are substituted in equation (15), we get $\pi_{t-1}=\pi_{t}=-\rho$. In other words, when there are no shocks, if the inherited inflation happens to be equal to the negative of the natural (long-run) real interest rate, then that inflation rate repeats itself ad infinitum. This is the deflationary long-run equilibrium of section 3 .

The unstable nature of the deflationary long-run equilibrium can now be proved. If we subtract $-\rho$ from both sides of equation (15) and rearrange and collect the terms, we get

$$
\pi_{t}-(-\rho)=\frac{\pi_{t-1}-(-\rho)+\nu_{t}+\phi \epsilon_{t}}{1-\alpha \phi}
$$


When there are no shocks $\left(\epsilon_{t}=\nu_{t}=0\right)$, we get

$$
\pi_{t}-(-\rho)=\frac{1}{1-\alpha \phi} \cdot\left(\pi_{t-1}-(-\rho)\right)
$$

As we have assumed $0<1-\alpha \phi<1$ - see section 4.1 -it follows that $1 /(1-\alpha \phi)>1$. Therefore, the gap between inflation and the deflationary long-run equilibrium rate of inflation retains its sign and increases - in absolute value - over time (as long as there are no shocks and the model's parameters stay constant). In other words, if the ZLB is binding $\left(\pi_{t-1}<\pi_{t-1}^{c}\right)$, the inflation rate $\left(\pi_{t}\right)$ diverges monotonically from the deflationary long-run equilibrium inflation rate $(-\rho)$.

We can summarize our convergence results as follows:

Proposition 1. Assume there are no shocks. If $\pi_{t-1}>-\rho$, the economy converges to the orthodox long-run equilibrium. If $\pi_{t-1}=-\rho$, the economy stays in the deflationary long-run equilibrium. If $\pi_{t-1}<-\rho$, the economy stays in a deflationary spiral. 


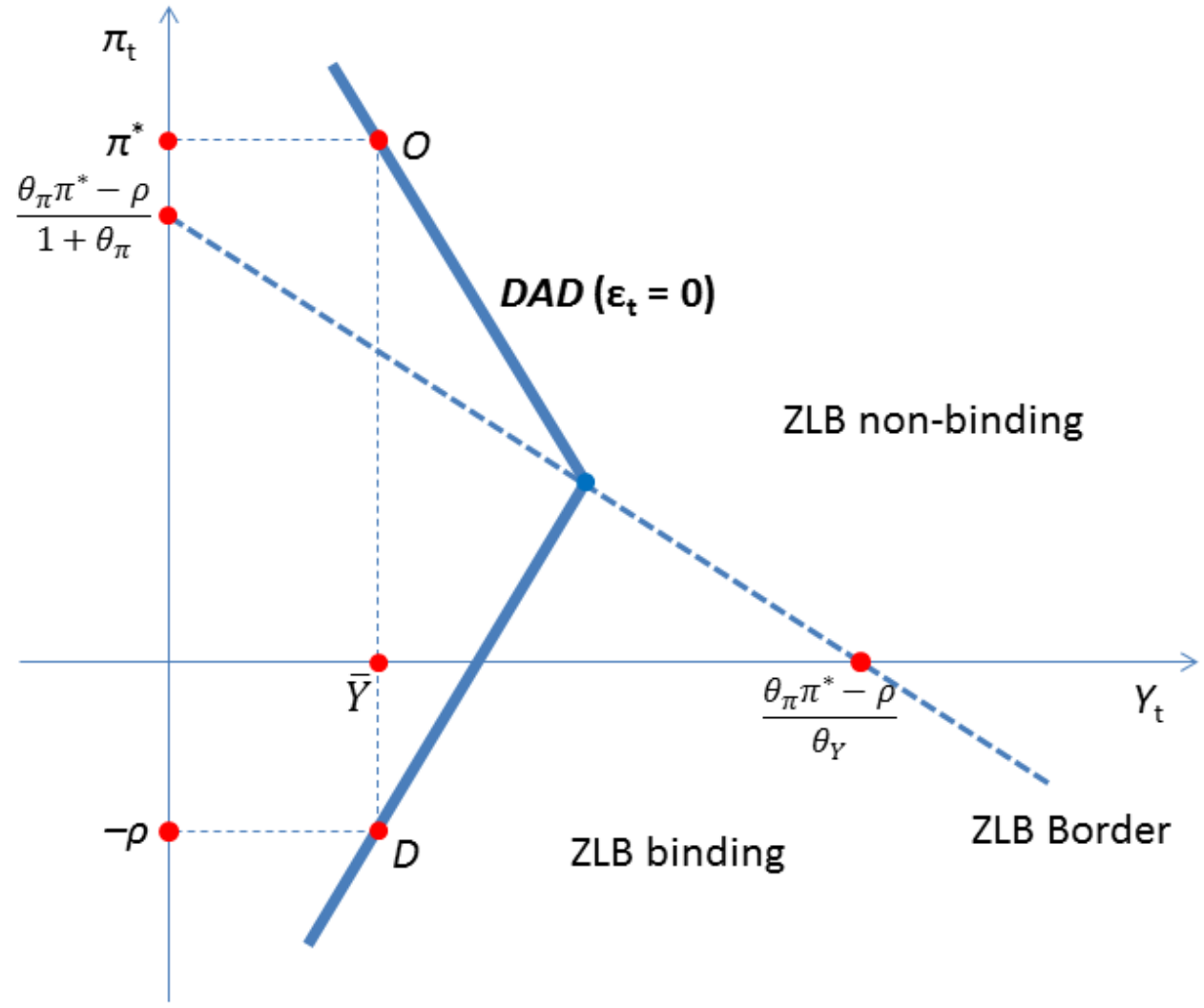

Figure 1: The Kinked DAD Curve is shown here. It is assumed that $\epsilon_{t}=0$ and $\bar{Y}_{t}=\bar{Y}$ for all $t$. 


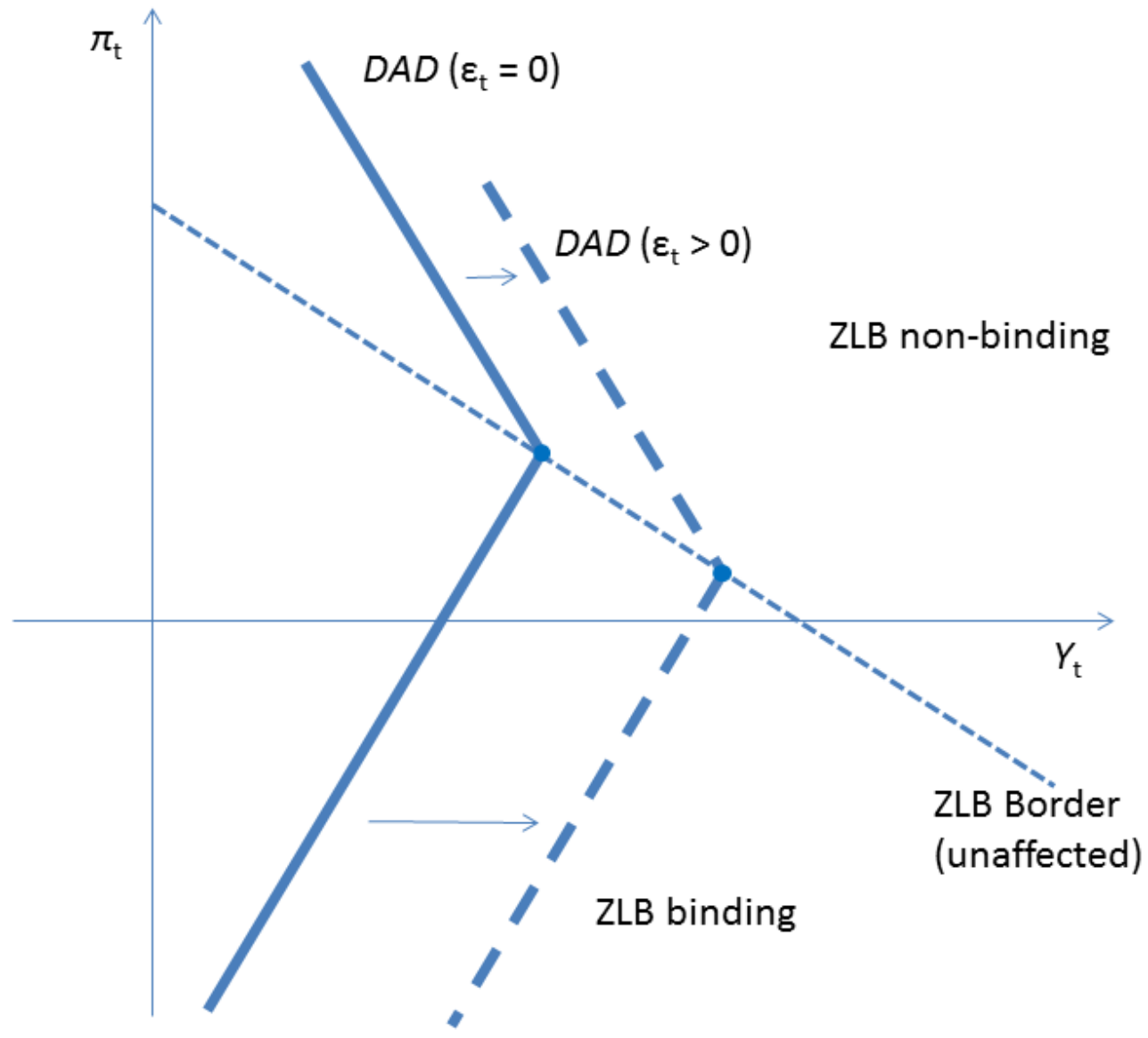

Figure 2: Expansionary fiscal policy $\left(\epsilon_{t} \uparrow\right)$ shifts the kinked DAD curve right without moving the ZLB border. 


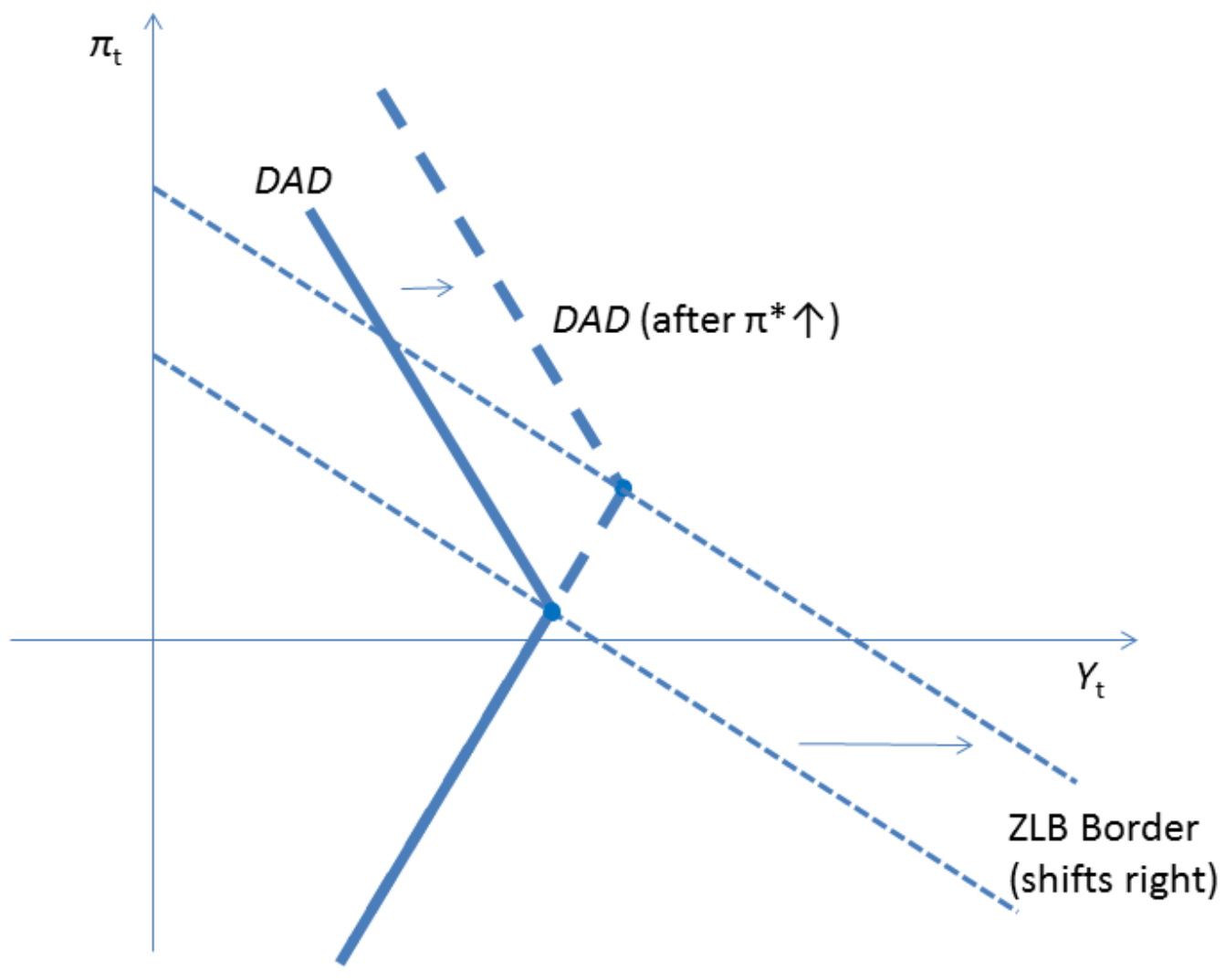

Figure 3: Expansionary monetary policy $\left(\pi^{*} \uparrow\right)$ shifts the ZLB border and the part of the DAD above the ZLB border to the right. The part of the DAD below the ZLB border just gets extended. 


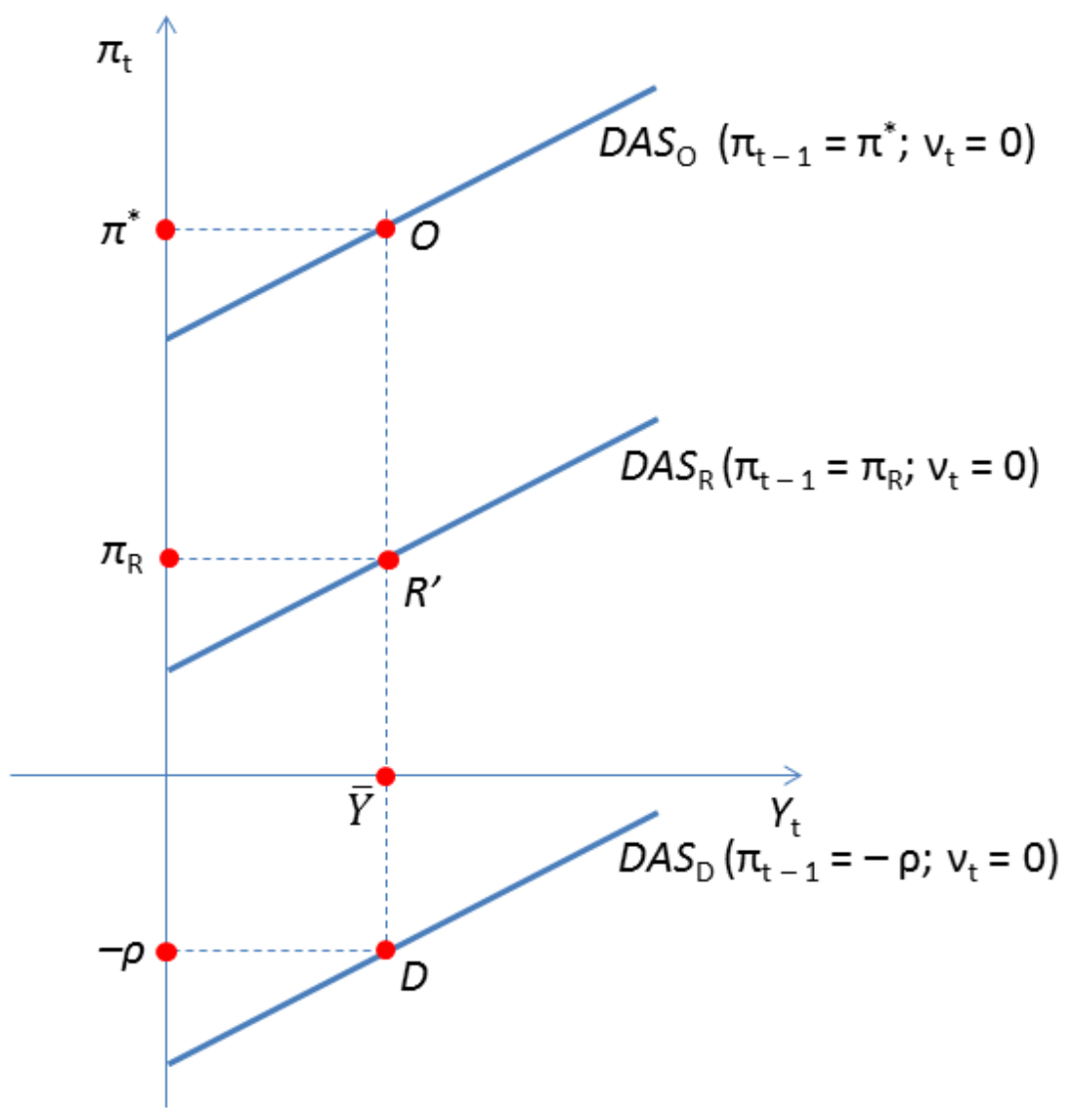

Figure 4: The DAS Curve is shown here. It is assumed that $\nu_{t}=0$ and $\bar{Y}_{t}=\bar{Y}$ for all $t$. 


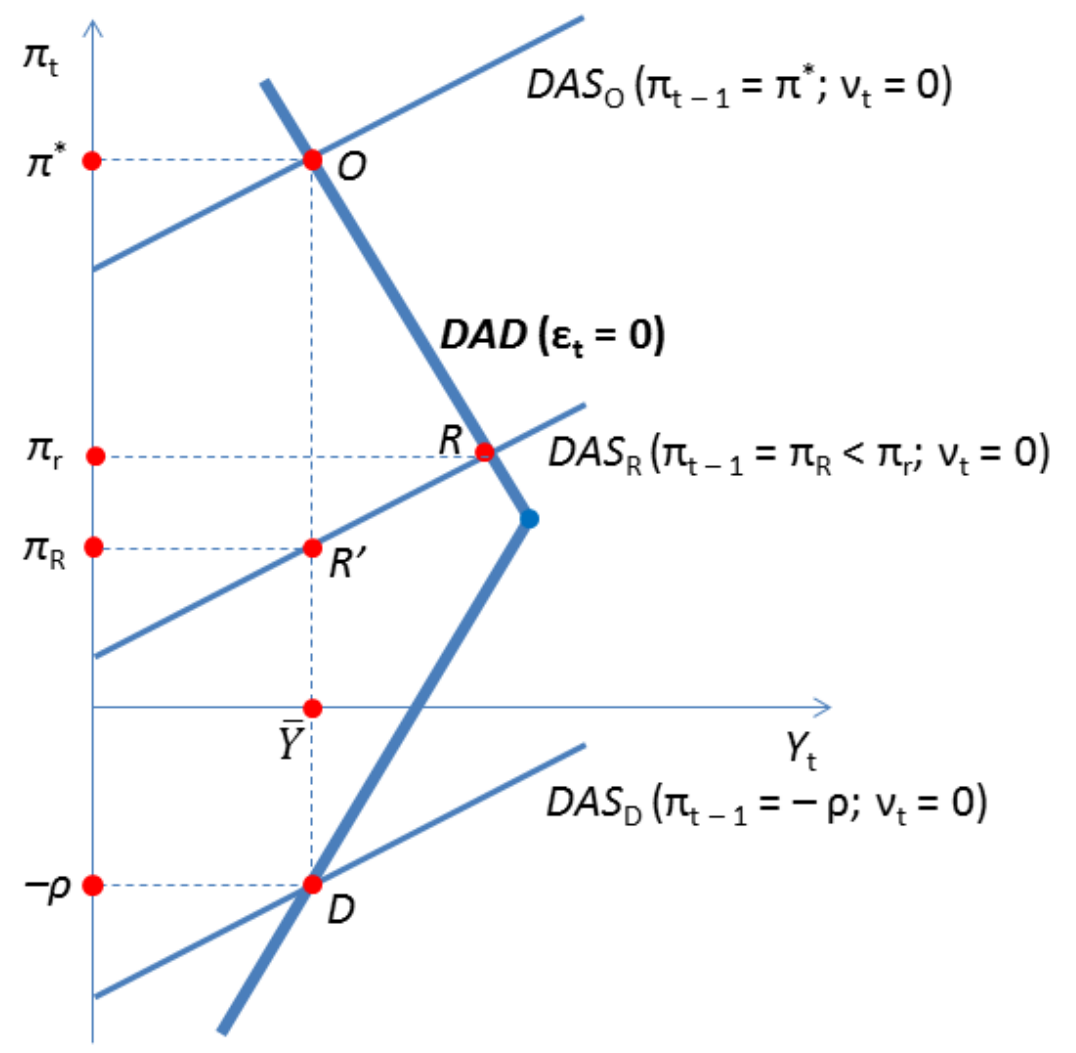

Figure 5: Both shocks are assumed zero. 


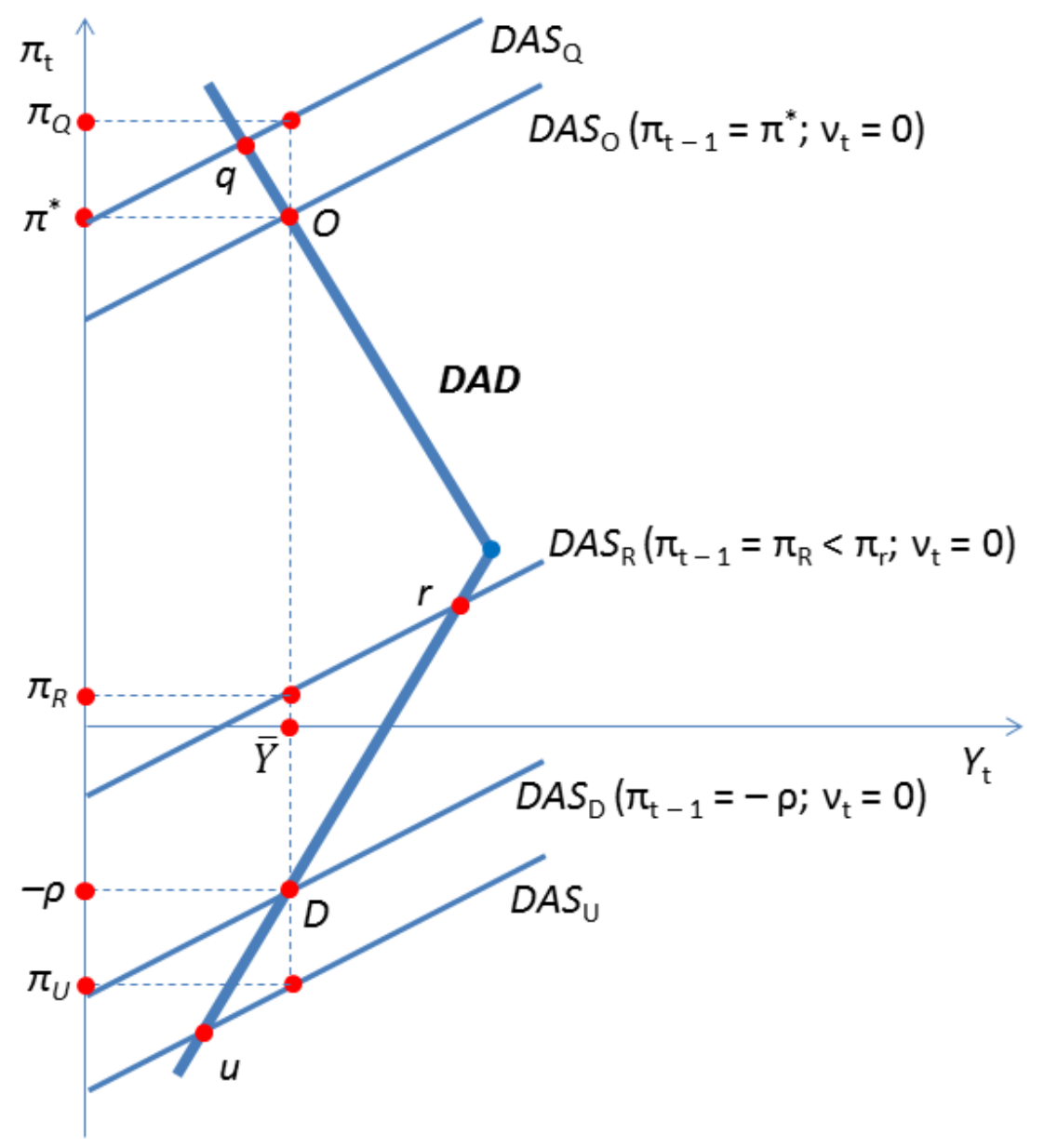

Figure 6: The orthodox equilibrium, $O$, is stable and the deflationary equilibrium, $D$, is unstable. 

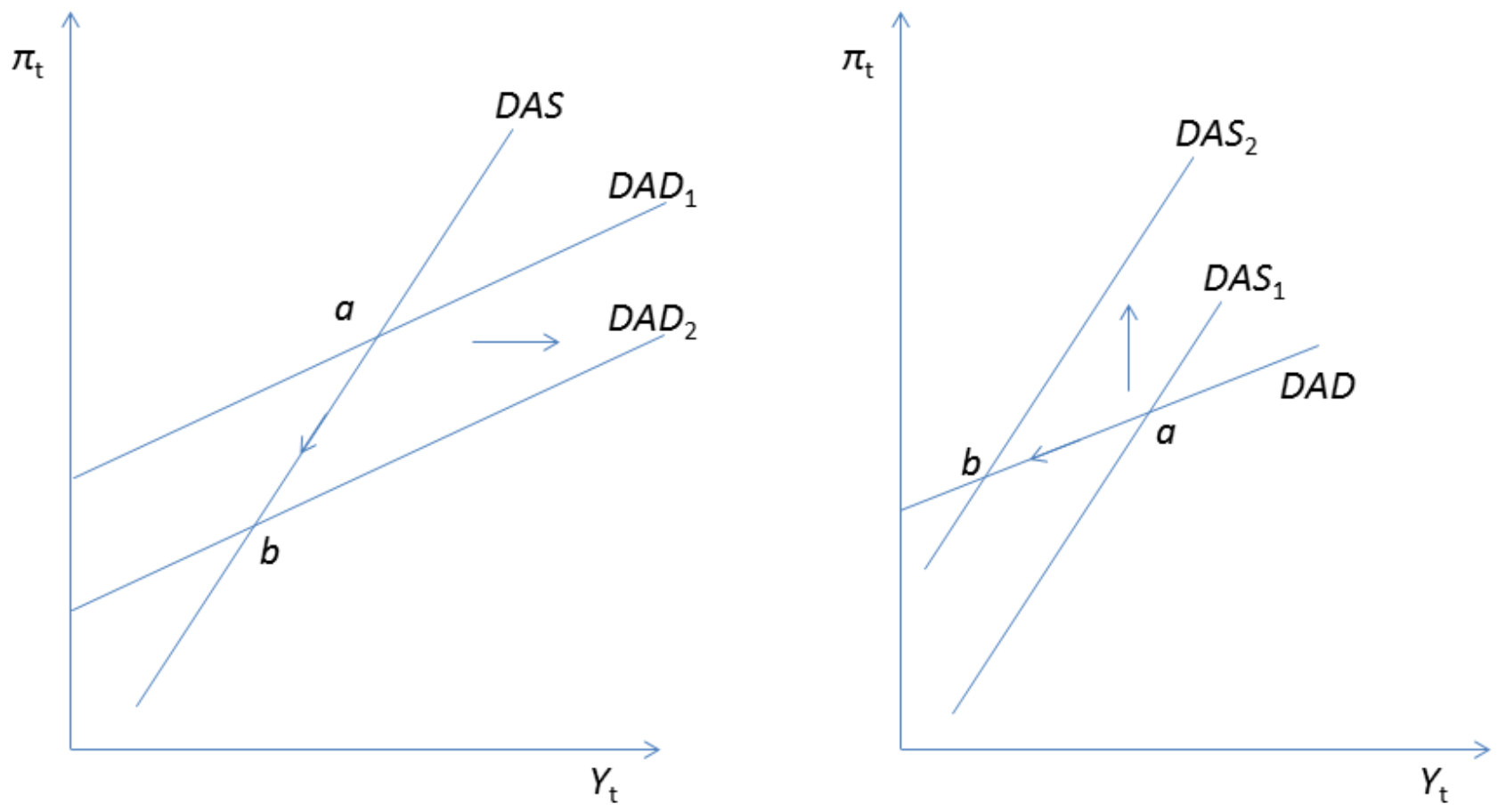

Figure 7: If DAS is steeper than DAD, a demand stimulus leads to lower output and lower inflation (left) and a supply shock leads to lower inflation (right). 


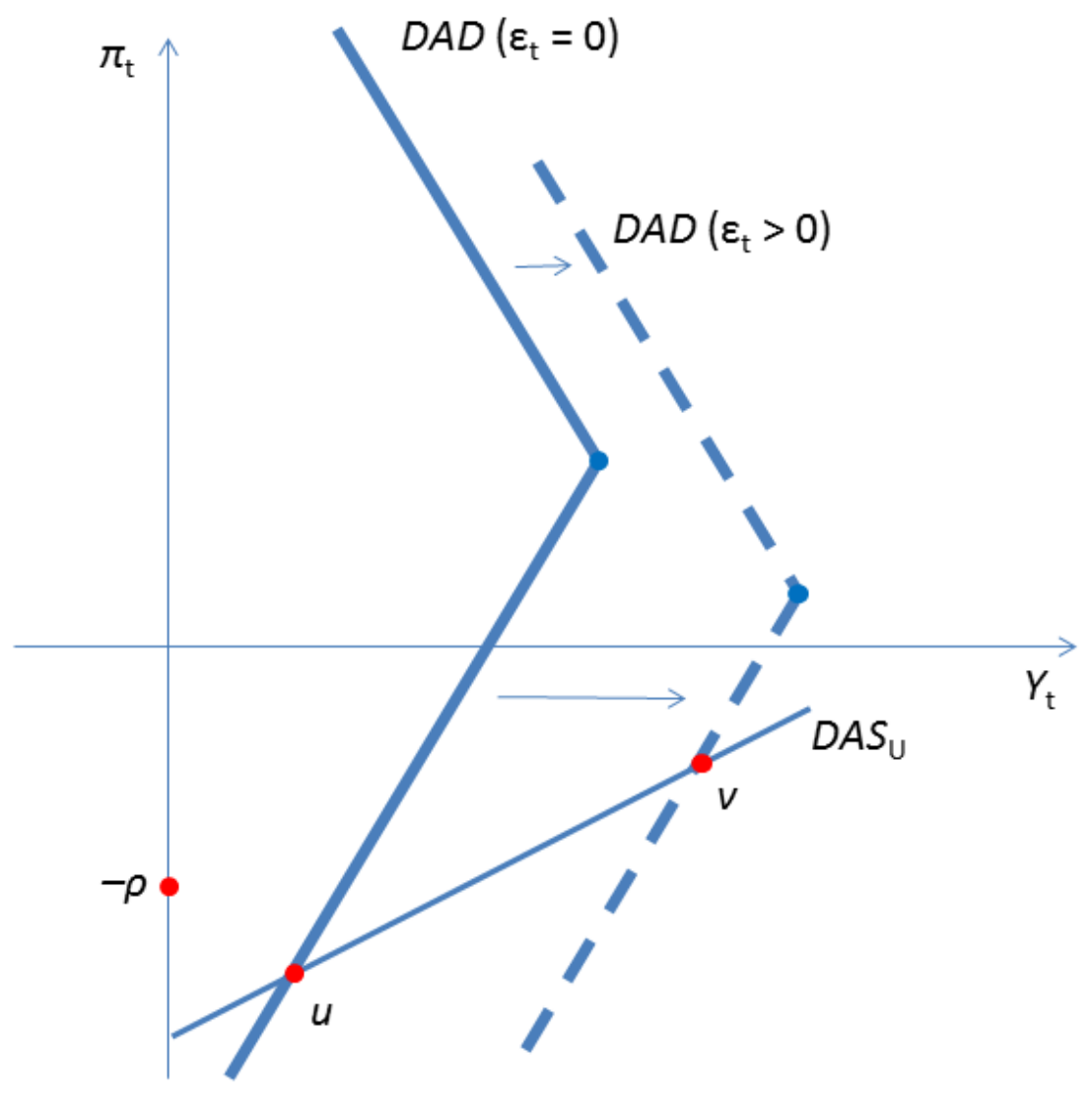

Figure 8: Expansionary fiscal policy and the deflationary spiral. 


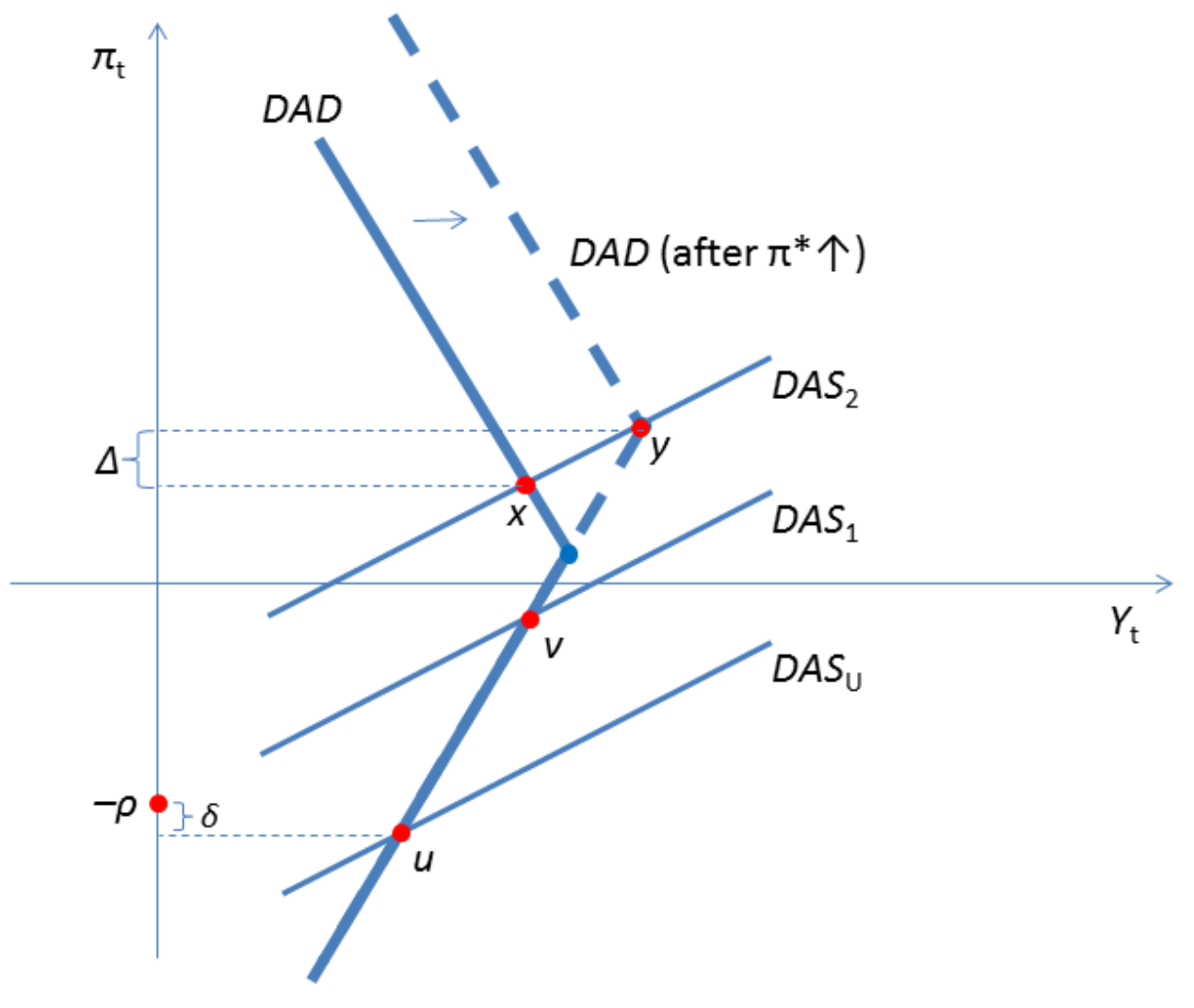

Figure 9: Expansionary monetary policy and the deflationary spiral. 